Special Section: Erosion and

Lateral Surface Processes

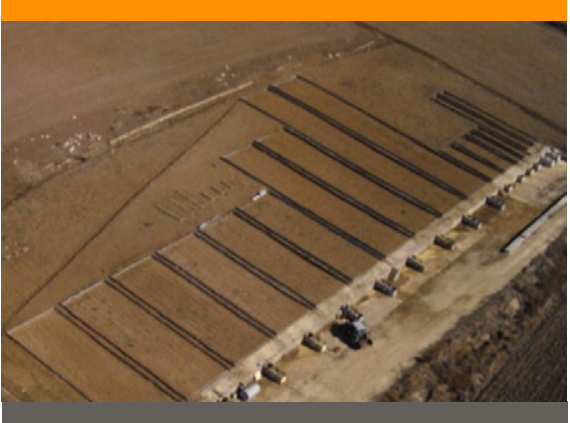

Core Ideas

- The physical model concept allows testing of the reliability of soil loss predictions.

- This concept was applied by using

the original and a new criterion in

southern Italy.

- The new criterion was generally

more restrictive than the original one.

V. Bagarello and V. Pampalone, Dep. of Agricultural, Food and Forest Sciences, Univ. of Palermo, Viale delle Scienze, Building 4, 90128 Palermo; V. Ferro, Dep. of Earth and Marine Science, Univ. of Palermo, Via Archirafi 20,90123 Palermo, Italy. *Corresponding author (vincenzo.pampalone@unipa.it).

Received 7 June 2017.

Accepted 23 July 2017.

Citation: Bagarello, V., V. Ferro, and V. Pampalone. 2017. Comparing two applicative criteria of the soil erosion physical model concept. Vadose Zone J. 16(12). doi:10.2136/vzj2017.06.0117

Vol. 16, Iss. 12, 2017

(C) Soil Science Society of America

5585 Guilford Rd., Madison, WI 53711 USA.

All rights reserved.

\section{Comparing Two Applicative Criteria of the Soil Erosion Physical Model Concept}

\section{Vincenzo Bagarello, Vito Ferro, and Vincenzo Pampalone*}

The physical model represented by a replicated plot has been suggested to be the best possible, unbiased, real world model to predict plot soil erosion. The aim of this investigation was to compare the original applicative criterion of the physical model concept proposed by Nearing with that later suggested by Bagarello et al. The comparison was performed by using three empirical soil erosion models (the Universal Soil Loss Equation [USLE], a modified USLE [USLE-MM], and the Central and Southern Italy [CSI] model) and plot soil loss data collected at the experimental station of Sparacia, in Sicily (southern Italy). The investigation showed that (i) the new criterion was generally more restrictive, i.e., less prone to accept the similarity hypothesis between predictions and measurements, than the original one; (ii) the new criterion gave a similar number of acceptable predictions as the original one when absolute differences between measured and predicted soil losses by the replicated plot were associated with a frequency occurrence factor of 0.87; (iii) for both tested criteria, the percentage of acceptable predictions could be considered time independent, and consequently, the checked performances of the three soil loss models could be considered generally representative of their capability in predicting soil losses at the sampled site; (iv) with the exception of the calibrated USLE, the hypothesis that, according to the original criterion, an effectiveness coefficient greater and lower than 0.6 could be expected for a calibrated and uncalibrated model, respectively, was confirmed; and ( $v$ ) the new criterion allowed establishment of an effectiveness coefficient of 0.12 , which discriminates between uncalibrated and calibrated models.

Abbreviations: CSI, Central and Southern Italy; USLE, Universal Soil Loss Equation; USLEMM, a modified Universal Soil Loss Equation.

Predicting soil loss is necessary to establish appropriate soil conservation strategies, but the quality of the predictions is often unknown due to poor knowledge of the applicability of a selected soil erosion model in an area of interest. Erosion prediction technology can be characterized as empirically based and process oriented and/or physically based. Although process-oriented models produced major advancements in erosion prediction technology, they require many input parameters and, in addition, do not guarantee a gain in prediction accuracy compared with empirical models (Tiwari et al., 2000). Therefore, empirical soil loss models are still popular because they combine acceptable accuracy with the ability to use quite basic data (Risse et al., 1993).

Soil loss measurements have to be used to test the applicability of soil erosion models and particularly the empirical ones because their applicability is limited to the conditions (e.g., geographic conditions, rainfall regimes, temporal scale) for which they were developed.

The most common approach to test model capability in predicting soil loss is to compare estimated against measured values of plot soil loss. Nearing et al. (1999) stated that soil loss measurements are affected by a natural variability that determines an unexplained variance in runoff and soil loss measurements from plots having the same size, crop cover, soil type, and treatments and subjected to the same rainfall event. In other words, Nearing et al. (1999) hypothesized that the unexplained variance in measurements is due only to natural variability between replicated plots such as the heterogeneous properties of the soil covering the investigated area. They neglected the influence of the human factors 
that can affect the measured values. The effect of the human factor variability, which should be dependent on the soil loss measurement technique used, is mitigated by the use of a dimensionless variable such as the relative difference, $R_{\text {diff }}$, defined according to Nearing (2000). In addition, the use of a calibration curve in soil loss measured by a storage tank system (Bagarello and Ferro, 1998, 2017; Bagarello et al., 2004) allows systematic errors in sediment concentration measurement to be avoided. In other words, a systematic error in soil loss does not affect the $R_{\text {diff }}$ variable. Therefore, it has to be expected that a portion of any difference between measured and predicted erosion rates will be due to model error, while another portion will be due to unexplained variance of the measured sample value from the representative mean value for a particular treatment (Nearing et al., 1999). A limit to the accuracy of both empirical and process-oriented erosion models is their deterministic nature, which makes them unable to explain the natural variability of soil loss measurements. Nearing (1998) suggested that the best possible model to predict erosion from an area of land is a physical model of the area that has similar soil type, land use, size, shape, slope, and erosive inputs. Therefore, the physical model represented by a replicated plot has to be considered the best possible, unbiased, real world model. Some recent investigations (Bagarello and Ferro, 2012; Kinnell, 2016) supported this conclusion.

For evaluating the acceptability of a predictive model taking within-treatment variability of erosion plots into account, Nearing (2000) suggested verifying whether the difference between the estimated soil loss, $P$, and the measured value, $M$, falls within the population of differences between pairs of measured values. In particular, according to Nearing (2000), the relative difference, $R_{\text {diff }}$, is calculated as

$$
R_{\text {diff }}=\frac{P-M}{P+M}
$$

and the effectiveness coefficient, $e$, is calculated as the fraction of data points in the considered set for which $R_{\text {diff }}$ falls within the $95 \%$ occurrence interval. This interval was derived by using plot soil loss measurements and predictions from the physical model represented by the replicated plots (Nearing, 2000).

A recent investigation performed at the Sparacia experimental station partially supported the conclusion that the method proposed by Nearing (2000) should be generally applicable for model validation studies (Bagarello and Ferro, 2012).

An alternative criterion to evaluate plot soil erosion predictions on the basis of the physical model concept was developed more recently by Bagarello et al. (2013a), using the plot soil loss data collected at the Sparacia and Masse stations, in Sicily (southern Italy) and Umbria (central Italy), respectively. According to this new criterion, the estimated soil loss $P$ is acceptable if the absolute difference with the measured soil loss, $|P-M|$, is lower than the value calculated by a power equation that predicts, for a given soil loss value $M$, the mean absolute difference associated with another identical sampled plot.

The general objective of this investigation was to compare the two applicative criteria of the physical model concept through three soil erosion empirical models (the USLE, USLE-MM, and the CSI model) and soil loss data collected on plots of different length and steepness at the Sparacia experimental station.

\section{Overview of the Soil Erosion Models}

The USLE (Wischmeier and Smith, 1978) and its revised version, the Revised USLE (RUSLE, Renard et al., 1997), are the most widely used empirical models for estimating plot soil loss. The USLE-RUSLE model predicts average annual soil loss but it has also been used for time intervals shorter than the mean annual one (Bagarello and Ferro, 2004; Bagarello et al., 2008; Hann and Morgan, 2006).

For a bare fallow plot with cultivation up and down the slope, the event soil loss, $A_{\mathrm{e}}\left(\mathrm{M} \mathrm{L}^{-2}\right)$, calculated with the USLE-RUSLE is

$$
A_{\mathrm{e}}=\mathrm{EI}_{30} K_{\mathrm{e}} L S
$$

where $\mathrm{EI}_{30}\left(\mathrm{M} \mathrm{L} \mathrm{T}^{-3}\right)$ is the event erosivity index, given by the product of the total kinetic energy of the rainstorm, $E\left(\mathrm{M} \mathrm{T}^{-2}\right)$, and the maximum 30-min intensity, $I_{30}\left(\mathrm{~L} \mathrm{~T}^{-1}\right)$ (Wischmeier and Smith, 1978), $K_{\mathrm{e}}\left(\mathrm{T}^{3} \mathrm{~L}^{-3}\right)$ is the soil erodibility factor, $L$ (dimensionless) is the slope length factor, and $S$ (dimensionless) is the slope steepness factor. Soil erodibility is dynamic and varies annually, seasonally, between storms, and within storms (e.g., Meyer and Harmon, 1992; Sanchis et al., 2007). According to Kinnell (2007), however, in the context of Eq. [2] the soil erodibility factor is assumed to remain constant with time, and therefore it coincides with the soil erodibility factor, $K$, used to predict long-term soil loss. For the Sparacia's soil, the nomograph by Wischmeier et al. (1971) yielded a value of the soil erodibility factor of 0.021 t ha h ha ${ }^{-1} \mathrm{MJ}^{-1} \mathrm{~mm}^{-1}$ while a locally calibrated version of the USLE requires an experimental value of the soil erodibility factor (Bagarello et al., 2012). The topographic factor, $L S$, is calculated according to the relationships proposed by Renard et al. (1997) and Nearing (1997).

When the runoff amount at the event temporal scale is known, event soil loss can be predicted using the $Q_{\mathrm{R}} \mathrm{EI}_{30}$ index, where $Q_{\mathrm{R}}$ is the dimensionless runoff coefficient. By using simultaneous measurements of runoff and soil loss from individual plots of different lengths operating at the Sparacia site, Bagarello et al. (2010) proposed the following equation: 


$$
A_{\mathrm{e}}=\left(Q_{\mathrm{R}} \mathrm{EI}_{30}\right)^{b_{1}} K_{\mathrm{MM}} L S
$$

where $b_{1}$ is an empirical coefficient greater than unity, $\left(Q_{\mathrm{R}} \mathrm{EI}_{30}\right)^{b 1}$ is the erosivity index and $K_{\mathrm{MM}}\left(\mathrm{M} \mathrm{L}^{-2}\right.$ per unit erosivity index) is the soil erodibility factor. Equation [3] represents a modified version of the USLE-M (Kinnell, 1997, 2003; Kinnell and Risse, 1998) and therefore it was named the USLE-MM. The investigation by Bagarello et al. (2013b) yielded $b_{1}=1.45, K_{\mathrm{MM}}=0.031$, and the following expression of the $L$ topographic factor for use with the USLE-MM:

$L=\left(\frac{\lambda}{22}\right)^{1.88}$

where $\lambda(\mathrm{m})$ is the slope length. Therefore, the event soil loss per unit plot area at the Sparacia experimental site can be predicted by

$A_{\mathrm{e}}=\left(Q_{\mathrm{R}} \mathrm{EI}_{30}\right)^{1.45} 0.031\left(\frac{\lambda}{22}\right)^{1.88} S$

Soil loss for an event, $A_{\mathrm{e}}\left(\mathrm{M} \mathrm{L}^{-2}\right)$, is given by the product of the runoff amount for the event, $V_{\mathrm{e}}\left(\mathrm{L}^{3} \mathrm{~L}^{-2}\right)$, and the bulk sediment concentration for the event, $C_{\mathrm{e}}\left(\mathrm{M} \mathrm{L}^{-3}\right)$ :

$A_{\mathrm{e}}=C_{\mathrm{e}} V_{\mathrm{e}}$

Kinnell (1997) suggested that the sediment concentration for individual rainfall events is linearly dependent on the USLE and/ or RUSLE event rainfall erosivity index, $\mathrm{EI}_{30}$, per unit quantity of rain, $h_{\mathrm{e}}$. According to Bagarello et al. (2010), the relationship between $C_{\mathrm{e}}$ and $\mathrm{EI}_{30} / h_{\mathrm{e}}$ was not linear for the clay soil of Sparacia and, for a given value of $\mathrm{EI}_{30} / h_{\mathrm{e}}, C_{\mathrm{e}}$ increased with $V_{\mathrm{e}}$. Based on these findings, the following empirical relationship for estimating sediment concentration was deduced by Bagarello et al. (2011) using data collected at the Sparacia area on bare plots differing in length:

$C_{\mathrm{e}}=b_{2} V_{\mathrm{e}}^{0.0203 \lambda}\left(\frac{\mathrm{EI}_{30}}{h_{\mathrm{e}}}\right)$

where $b_{2}$ is an empirical coefficient. Therefore, it follows from Eq. $[6]$ and [7] that

$A_{\mathrm{e}}=b_{2} V_{\mathrm{e}}^{1+0.0203 \lambda}\left(\frac{\mathrm{EI}_{30}}{h_{\mathrm{e}}}\right)$

The mathematical structure of Eq. [8] suggested that, for a bare soil, the coefficient $b_{2}$ is influenced by both soil erodibility and slope steepness, s. The more general form of Eq. [8] was obtained by Bagarello et al. (2011) by the empirical analysis of a large data set including measurements collected at three stations located in central (Masse and Caratozzolo) and southern (Sparacia) Italy. The analysis developed by Bagarello et al. (2011) suggested that the percentage of silt, si (\%), can be assumed as an estimator of soil erodibility and that the $b_{2} /$ si ratio depends on $s$ according to a power relationship. Finally, the more general form of Eq. [8] is

$A_{\mathrm{e}}=0.7606 \mathrm{si} \mathrm{s}^{3.0543} V_{\mathrm{e}}^{1+0.0203 \lambda}\left(\frac{E I_{30}}{h_{\mathrm{e}}}\right)$

The acronym CSI was used for this empirical equation to denote the origin of the data (central and southern Italy).

Among the three models selected in this investigation, the USLE differs from the USLE-MM and CSI model as the only one able to estimate soil loss without using runoff information. Previous studies performed in different experimental areas confirmed that the USLE is surely characterized by an estimate performance worse than that obtainable by an empirical runoff-driven model (Bagarello and Ferro, 2004; Bagarello et al., 2008, 2010, 2015; Di Stefano et al., 2017a, 2017b; Gao et al., 2012; Kinnell and Risse, 1998; Kinnell, 2016). Even if the availability of all experimental information for fitting should improve the robustness of an empirical model, to compare the performance of models calibrated by the same database, the versions of the CSI model and the USLE-MM calibrated by Bagarello et al. (2011) and Bagarello et al. (2013b), respectively, were used. The comparability of the calibrated USLE with the CSI and USLE-MM was assured by calibrating the USLE in this investigation with the same database. This last circumstance avoided a possible effect of the calibration sample size on the assessment of the models' reliability. In this study, the uncalibrated USLE, i.e., the USLE with the soil erodibility factor calculated by the nomograph of Wischmeier et al. (1971) and the $L S$ factor estimated by literature relationships (Renard et al., 1997; Nearing, 1997), was also used. These choices were aimed at, respectively, (i) comparing versions of the calibrated USLE, USLE-MM, and CSI models characterized by homogeneity in terms of Sparacia data used for their calibration, and (ii) testing if the expected level of error suggested by Nearing (2000) from an uncalibrated erosion model (i.e., the USLE) was usable in the sampled environment.

\section{Materials and Methods}

The experimental station for soil erosion measurement, Sparacia, of the Department of Agricultural, Food and Forest Sciences of Palermo University, is located in western Sicily, southern Italy, approximately $100 \mathrm{~km}$ south of Palermo (Bagarello and Ferro, 2004). The area has a typical Mediterranean semiarid climate, with an average annual rainfall of $700 \mathrm{~mm}$. The soil is a Vertic Haploxerept (Soil Survey Staff, 2006) with a clay texture and a negligible gravel content. The depth of the A horizon is approximately $0.30 \mathrm{~m}$. Two plots of 44 by $8 \mathrm{~m}$, two plots of 33 by $8 \mathrm{~m}$, six plots of 22 by $8 \mathrm{~m}$, two plots of 22 by $2 \mathrm{~m}$, two plots of 11 by $4 \mathrm{~m}$, and two plots of 11 by $2 \mathrm{~m}$ were installed on a $14.9 \%$ slope. This $14.9 \%$ slope is equipped with a recording rain gauge operating at 1 -min time intervals. Two additional plots of 22 by $6 \mathrm{~m}$ were 
established on a $22 \%$ slope and another two similar plots were established on a $26 \%$ slope within the Sparacia experimental area. These four plots are equipped with another recording rain gauge operating at 1-min time intervals.

Runoff and associated sediments from each plot were intercepted by a gutter placed along the lower end of the plot and then collected into a storage system consisting of tanks of known geometric characteristics, each having a capacity of approximately $1 \mathrm{~m}^{3}$, that were arranged in series at the base of each plot. Total runoff and soil loss were measured after each erosive event (i.e., a natural event producing measurable runoff) or, occasionally, after a series of events if they were separated by a very short time interval, using the methods described by Bagarello and Ferro (1998), Bagarello et al. (2004), and Carollo et al. (2016).

All measurements were performed on bare soil. The knowledge of the event runoff amount was necessary only for using the USLE-MM and the CSI model. However, to use the same database, the analysis was developed using only data from individual plots when both soil loss and runoff measurements were available.

For evaluating the temporal variability of the effectiveness coefficient $e$ calculated by the two applicative criteria of the physical model concept, three different databases were arranged including measurements collected until a fixed date (Table 1). In particular, the first database (Database 1, 2002-2008, sample size $N=$ 352) includes the measurements used for calibrating the USLE, the USLE-MM, and CSI model; the second database (Database 2, 2002-2012, $N=476$ ) includes the measurements used by

Table 1. Summary statistics of event rainfall amount $\left(b_{\mathrm{e}}\right)$, single storm erosivity index $\left(\mathrm{EI}_{30}\right)$, event runoff amount $(V)$, event runoff coefficient $\left(Q_{\mathrm{R}}\right)$, and event soil loss per unit area $\left(A_{\mathrm{e}}\right)$ for the three databases used in this investigation.

\begin{tabular}{|c|c|c|c|c|c|c|c|}
\hline Database & Sampling period & Statistic & $b_{e}$ & $\mathrm{EI}_{30}$ & $V_{e}$ & $Q_{R}$ & $A_{e}$ \\
\hline \multirow{6}{*}{1} & \multirow{6}{*}{$\begin{array}{l}\text { Jan. 2002-Dec. } 2008 \\
(N=352) \dagger\end{array}$} & & $\mathrm{mm}$ & $\mathrm{MJ} \mathrm{mm} \mathrm{ha}{ }^{-1} \mathrm{~h}^{-1}$ & $\mathrm{~mm}$ & & $\mathrm{~kg} \mathrm{~m}^{-2}$ \\
\hline & & $\min$. & 11.8 & 8.1 & 0.04 & 0.002 & 0.0001 \\
\hline & & $\max$. & 97.8 & 988.8 & 40.26 & 0.81 & 27.3 \\
\hline & & mean & 37.5 & 164.5 & 5.07 & 0.13 & 1.1 \\
\hline & & median & 32.8 & 113.0 & 2.83 & 0.09 & 0.2 \\
\hline & & $\mathrm{CV}$ & 0.55 & 1.03 & 1.19 & 0.99 & 2.35 \\
\hline \multirow[t]{5}{*}{2} & \multirow{5}{*}{$\begin{array}{l}\text { Jan. 2002-Mar. } 2012 \\
(N=476)\end{array}$} & $\min$. & 11.8 & 8.1 & 0.04 & 0.002 & 0.0001 \\
\hline & & $\max$ & 97.8 & 988.8 & 41.63 & 0.89 & 27.3 \\
\hline & & mean & 40.7 & 151.6 & 6.11 & 0.15 & 1.1 \\
\hline & & median & 36 & 98.3 & 3.90 & 0.12 & 0.2 \\
\hline & & $\mathrm{CV}$ & 0.51 & 1.02 & 1.07 & 0.97 & 2.25 \\
\hline \multirow[t]{5}{*}{3} & \multirow{5}{*}{$\begin{array}{l}\text { Jan. } 2002-\text { Oct. } 2016 \\
(N=574)\end{array}$} & $\min$. & 11.8 & 8.1 & 0.03 & 0.001 & 0.0001 \\
\hline & & $\max$ & 145.8 & 988.8 & 41.63 & 0.89 & 27.3 \\
\hline & & mean & 44.2 & 148.3 & 5.99 & 0.14 & 1.0 \\
\hline & & median & 38 & 100.2 & 3.95 & 0.11 & 0.2 \\
\hline & & $\mathrm{CV}$ & 0.62 & 0.98 & 1.04 & 0.98 & 2.35 \\
\hline
\end{tabular}

$\dagger N$, sample size.
Bagarello et al. (2013a) for developing the new applicative criterion of the physical model concept; and the third database (Database 3, 2002-2016, $N=574$ ) includes all available measurements to date. The databases were compiled pooling together measurements performed for different $\lambda-s$ combinations, and their summary statistics are reported in Table 1 . The sample size, $N$, increases by about 35\% from Database 1 to Database 2 and by 21\% from Database 2 to Database 3. The wide ranges of the measured variables for each database suggest a good representativeness for the purposes of this investigation. An increasing tendency of the mean event rainfall amount associated with a decreasing trend of the mean single storm erosivity index is detectable, while no trend was detectable for $V_{\mathrm{e}}, Q_{\mathrm{R}}$, or $A_{\mathrm{e}}$. The measurement relative variability is generally independent of the database.

Using Database 1 and the relationships for calculating $L S$ by Renard et al. (1997) and Nearing (1997), the USLE was calibrated by the procedure of Foster et al. (1981) (Bagarello et al., 2012) obtaining a soil erodibility factor value, $K_{\mathrm{e}}$, of 0.035 tha h ha ${ }^{-1} \mathrm{MJ}^{-1} \mathrm{~mm}^{-1}$.

For applying the criterion proposed by Nearing (2000) (original criterion), the measured and predicted data pairs were listed and the relative difference was calculated by Eq. [1]. The 95\% occurrence interval was then computed for each data point using the following relationships derived by Nearing (2000) from event values of soil loss from seven sites in the United States, with 2061 replicated storm events in the data set, and also annual values of soil loss from 13 sites, with a total of 797 replicated pairs of plots:

$R_{\mathrm{diff}, \mathrm{INF}}=0.236 \log M-0.641$

$R_{\text {diff,SUP }}=-0.179 \log M+0.416$

where $R_{\text {diff,INF }}$ and $R_{\text {diff,SUP }}$ are the lower and the upper limits of the interval, and $M$ is the measured soil loss $\left(\mathrm{kg} \mathrm{m}^{-2}\right)$. The effectiveness coefficient $e$ was determined as the ratio between the number of predictions for which the calculated $R_{\text {diff }}$ value fell within the interval $\left(R_{\text {diff,INF }}-R_{\text {diff,SUP }}\right)$ and the total number of predictions. Nearing (2000) suggested that an effectiveness coefficient on the order of 0.6 is what can be expected at the most from uncalibrated erosion models while, in the case of a calibrated model, $e>0.6$ can be expected.

For applying the criterion proposed by Bagarello et al. (2013a) (the new criterion), the absolute difference $|P-M|$ was calculated and the effectiveness coefficient $e$ was determined as the fraction of data points in the considered set for which $|P-M|$ was lower than the value calculated by (Bagarello et al., 2013a)

$|P-M|=0.356 M^{0.91}$ 
Taking into account that Eq. [11] was developed using Database 2 , this database was applied in this study for all analyses with the only exception of that on temporal stability of the checked performances. Equation [11] was calibrated using measurements performed in two Italian sites and the performance of its applicability to other sites is currently not known.

\section{Results and Discussion}

According to the new criterion, a soil loss prediction $P$ can be considered acceptable when the following inequality is verified:

$|P-M| \leq 0.356 M^{0.91}$

which can be expressed as

$-0.356 M^{0.91} \leq P-M \leq 0.356 M^{0.91}$

The following relationship was obtained by dividing each member of the inequalities in Eq. [13] by $(P+M)$ :

$$
\frac{-0.356 M^{0.91}}{P+M} \leq \frac{P-M}{P+M} \leq \frac{0.356 M^{0.91}}{P+M}
$$

Using Eq. [14] has the advantage of expressing the criterion of Bagarello et al. (2013a), which was deduced by measurements in two Italian sites, in a more general form that is dimensionless and directly comparable with the results of Nearing (2000). In other words, the criteria of Nearing (2000) and of Bagarello et al. (2013a), obtained by measurements in different geographical areas, are now expressed in the same mathematical shape, which permits a direct comparison.

The new criterion is more restrictive than the original one, that is, it rejects the similarity hypothesis between $P$ and $M$ in a greater number of cases, if the upper and lower limits derived by the inequalities of Eq. [14] fall within the range bounded by Eq. [10a] and $[10 \mathrm{~b}]$. This result occurs for the $(M, P)$ pairs satisfying the following system:

$$
\left\{\begin{array}{l}
\frac{0.356 M^{0.91}}{P+M}<-0.179 \log (M)+0.416 \\
\frac{-0.356 M^{0.91}}{P+M}>0.236 \log (M)-0.641
\end{array}\right.
$$

which can be rewritten as

$$
\left\{\begin{array}{l}
P>f_{1}(M)= \\
\frac{0.356 M^{0.91}-M[-0.179 \log (M)+0.416]}{-0.179 \log (M)+0.416} \\
P>f_{2}(M)= \\
\frac{-0.356 M^{0.91}-M[0.236 \log (M)-0.641]}{0.236 \log (M)-0.641}
\end{array}\right.
$$

where $f_{1}$ and $f_{2}$ are two functional symbols. Plotting the $P=f_{1}(M)$ and $P=f_{2}(M)$ curves in the reference plane $(M, P)$ allows the region where both the inequalities in Eq. [16] are verified to be established. Taking into account that $P \geq 0$, the relationships $P=f_{1}(M)$ and $P=f_{2}(M)$ have to assume positive or zero values $\left[f_{1}(M) \geq 0\right.$ and $\left.f_{2}(M) \geq 0\right]$, therefore the straight line $P=0$ has to be considered for $f_{1}(M)<0$ and $f_{2}(M)<0$. Figure la shows that Region 1 , bounded by the straight line $P=0$ for $M<3.6 \mathrm{~kg} \mathrm{~m}^{-2}$, the $P=f_{1}(M)$ curve for $M \geq 3.6 \mathrm{~kg} \mathrm{~m}^{-2}$, and the axis of the ordinates, is distinguishable on the $M$ vs. $P$ plot, showing the zone where the new criterion is certainly more restrictive than the original one. An implication is that the $P=f_{1}(M)$ curve is sufficient to determine that region. In other words, for the $(M, P)$ pairs falling into that region, the expected effectiveness coefficient calculated by the new criterion is certainly lower than the original one. Applying a mathematical procedure similar to the one described above, Region 3 (Fig. 1a) is also distinguishable where the original criterion is certainly more restrictive than the new one. However, this Region 3 is characterized by measured soil
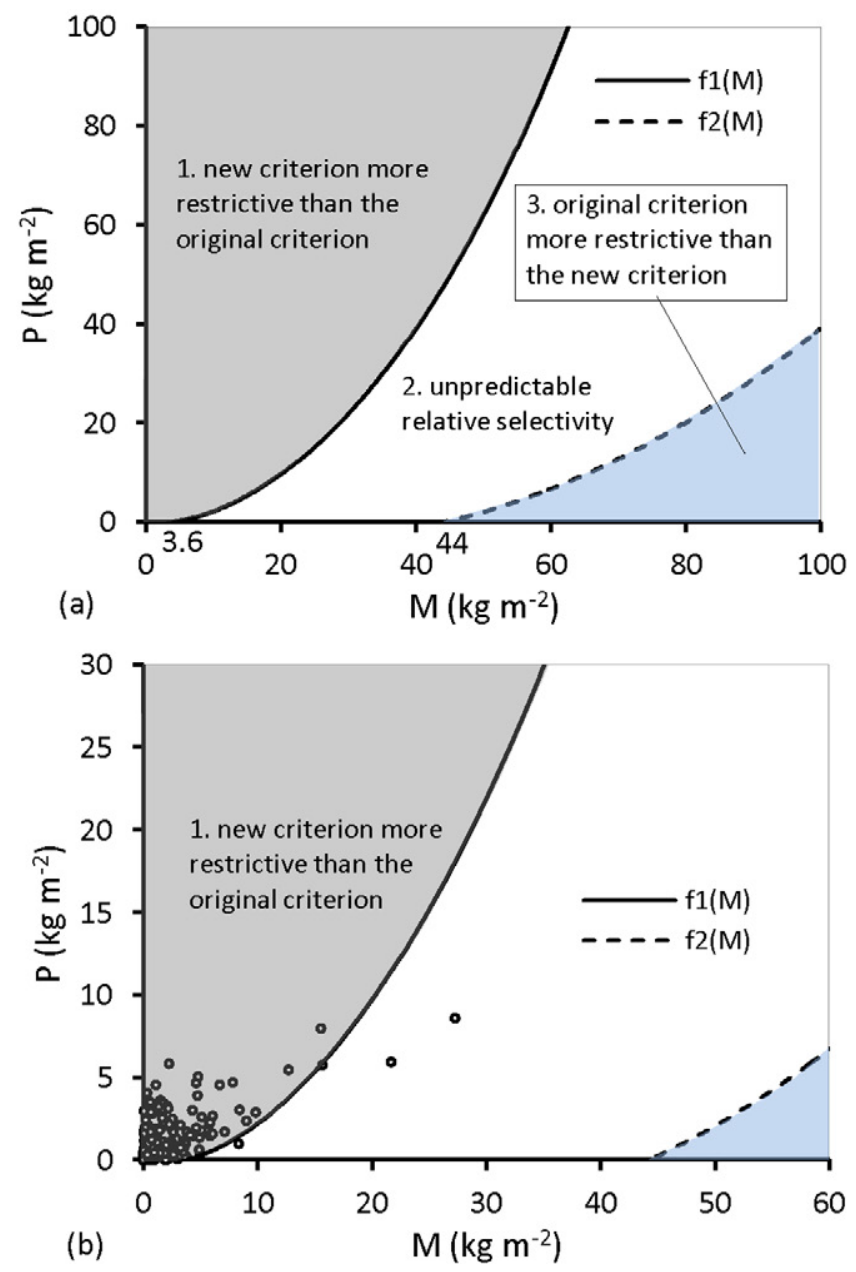

Fig. 1. (a) Plot of the three regions of the $(M, P)$ reference plane for comparing the selectivity of the original criterion and the new one, and (b) plot of the measured event soil loss values, $M$, included in Database 2 vs. the predicted ones, $P$, by the Central and Southern Italy (CSI) model. 
loss values $\geq 44 \mathrm{~kg} \mathrm{~m}^{-2}$, which are extremely high and, in practice, unrealistic at the event scale. An a priori conclusion on the relative selectivity of the two criteria cannot be drawn for the intermediate Region 2. Furthermore, Fig. $1 \mathrm{~b}$ shows, as an example for $P$ values predicted by the CSI model, that almost all the pairs $(M, P)$ fell within Region 1 and, as a consequence, it demonstrates that the new criterion is more restrictive than the original one in the range of the expected $M$ values.

For each of the three soil erosion models used, the values of the effectiveness coefficient $e$ calculated by the two criteria (Table 2) confirm that the new criterion is much more restrictive than the original one because the differences between corresponding $e$ values range from 0.29 to 0.54 . According to the original criterion, the USLE-MM was the most reliable model, among those tested, for estimating plot soil loss at the event temporal scale at the Sparacia station, followed by the CSI model, and the uncalibrated and calibrated USLE. According to the new criterion, the CSI model performed slightly better than the USLE-MM, and the two versions of the USLE were the least reliable models. Therefore, the order of reliability of the models strictly depends on the criterion used to rank them. However, for a given criterion, the performances of the USLE-MM and CSI model were similar because differences between the $e$ values were small in both cases $(\leq 0.04)$. Therefore, the reliability of the two models can be considered comparable, regardless of the applied criterion. The better performance of the USLE-MM and CSI model compared with the uncalibrated USLE was expected because the former two models were specifically developed for estimating event soil loss using runoff and they were calibrated, while the latter model was originally designed to predict long-term soil loss and it was uncalibrated. Table 2 also

Table 2. Values of the effectiveness coefficient $e$ determined by different applicative criteria of the physical model concept for three tested soil erosion models, the Universal Soil Loss Equation (USLE), a modified USLE (USLE-MM), and the Central and Southern Italy (CSI) model.

\begin{tabular}{l|l|l|l|l} 
Model & $\begin{array}{l}\text { Original } \\
\text { criterion }\end{array}$ & $\begin{array}{l}\text { New } \\
\text { criterion }\end{array}$ & $\begin{array}{l}\text { New criterion } \\
\text { (frequency } F=0.87)\end{array}$ & Envelope \\
\hline Uncalibrated USLE & 0.48 & 0.12 & 0.50 & 0.92 \\
Calibrated USLE & 0.43 & 0.14 & 0.40 & 0.84 \\
USLE-MM & 0.78 & 0.24 & 0.73 & 0.998 \\
CSI model & 0.74 & 0.27 & 0.78 & 0.998 \\
Mean & 0.61 & & 0.60 & \\
\hline
\end{tabular}

shows that only with the new criterion the effectiveness coefficient value of the uncalibrated USLE was smaller than that of the calibrated USLE. These two $e$ values (calibrated and uncalibrated USLE) remain at the lowest levels regardless of the considered criterion because the calibration procedure of the USLE did not yield an improvement of the lowest soil loss estimates (see the first two rows of Table 3).

Figure 2 shows the $1468(M,|P-M|)$ experimental pairs used by Bagarello et al. (2013a) to develop the new criterion based on Eq. [11] and the curve representative of Eq. [11]. In this figure, $P$ is equal to the soil loss prediction by the replicated plot. Equation [11] establishes, for a given soil loss value $M$, what is the mean absolute difference associated with the sampling of another, identical plot. In this investigation, the least restrictive criterion, using a relationship enveloping all data points, and an intermediate criterion between the regression line (Eq. [11]) and a data enveloping line were also tested. The intermediate criterion was developed by carrying out a frequency analysis of the data divided into half log-cycle intervals starting at $0.0003 \mathrm{~kg} \mathrm{~m}^{-2}$ and ending at $10 \mathrm{~kg}$ $\mathrm{m}^{-2}$. The two extreme half log-cycle intervals, which were outside this range, were not considered because of their small sample

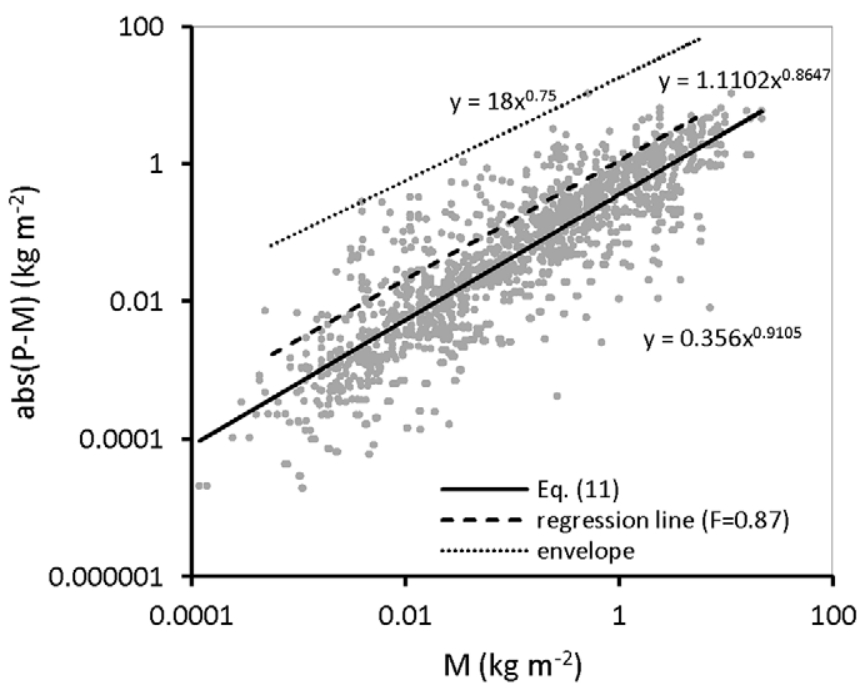

Fig. 2. Plot of the absolute difference in measurement of soil loss between replicated plots, $|P-M|$, vs. the measured value, $M$, (Bagarello et al., 2013a) and of Eq. [11], the regression line associated with a frequency $F=0.87$ and the data enveloping line.

Table 3. Values of the effectiveness coefficient $e$ arranged by using the range of measured soil loss determined by the original and new criteria for three tested soil erosion models, the Universal Soil Loss Equation (USLE), a modified USLE (USLE-MM), and the Central and Southern Italy (CSI) model.

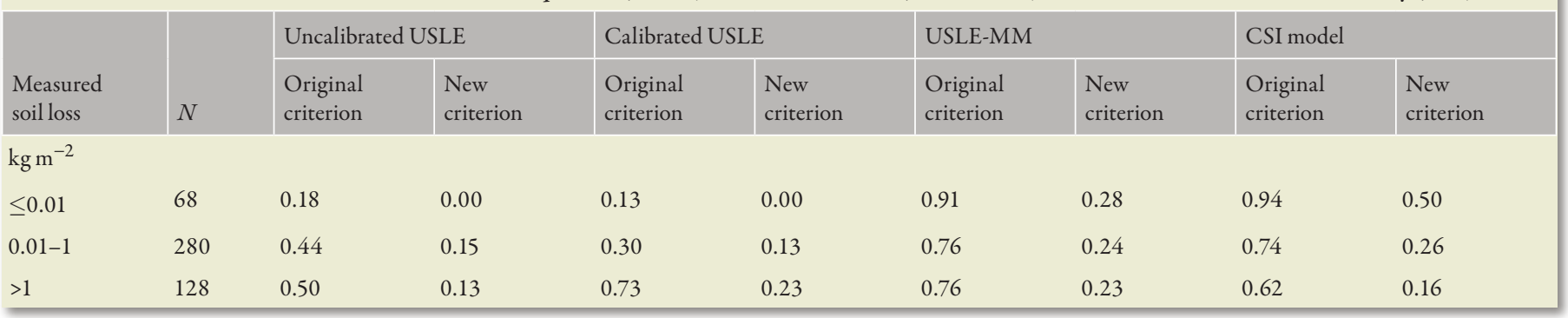


size. For the data points within each division, the value associated with a given frequency, $F$, was determined and a regression curve between these values and the measured ones was fitted (Fig. 2). The frequency, $F$, for which the new and the original criterion gave similar results was found to be 0.87 . In detail, for this value of $F$ the two criteria gave the same $e$ value averaged across the three models and very similar $e$ values for each model (Table 2). For decreasing values of the frequency from 0.87 to 0.5 , which practically yields Eq. [11], the new criterion becomes more and more restrictive than the original one, while the opposite obviously occurs for frequency
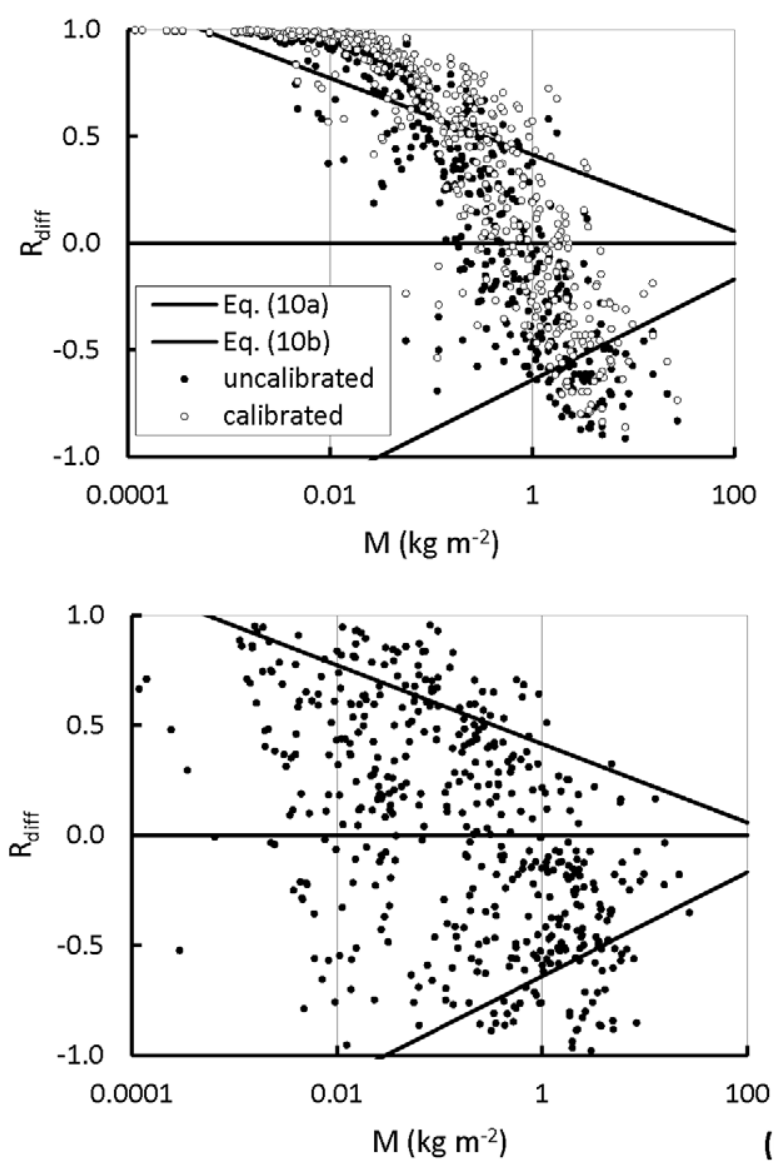

(a) USLE
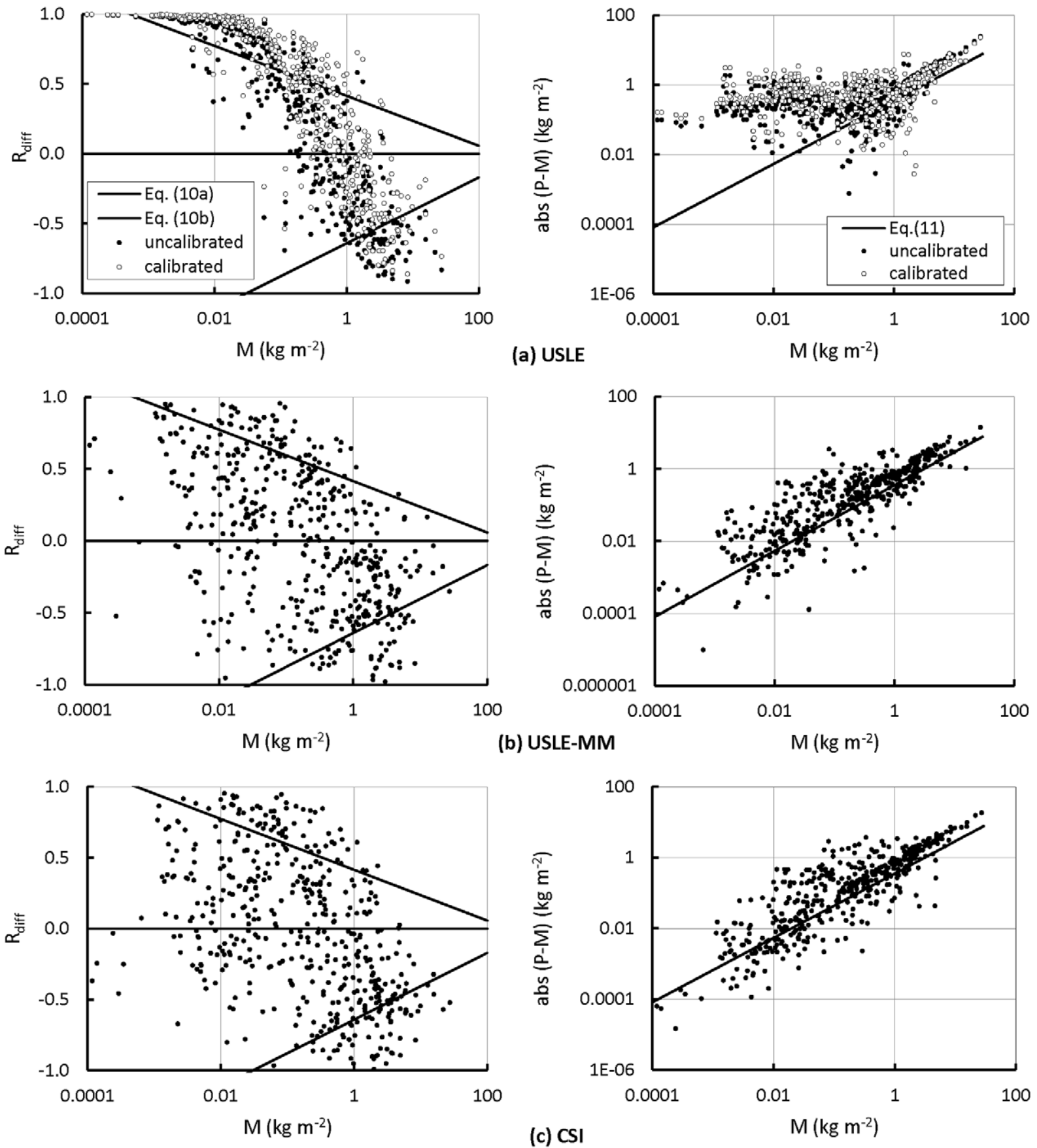

Fig. 3. Relative difference, $R_{\text {diff, }}$ plotted against the measured value, $M$, and absolute difference between predicted and measured values, $|P-M|$ plotted against $M$ for (a) the USLE, (b) a modified USLE (USLE-MM), and (c) the Central and Southern Italy (CSI) model. 
lower range and underpredicted in the upper range of the soil loss values, but the effect was not as apparent as for the USLE predictions because the scatter of the data points was noticeable. The new criterion using Eq. [11] does not allow detection of this tendency because it is based on the assumption that $|P-M|$ is enough to establish the accuracy level of the predictions (Fig. 3).

Both the original and new criteria accept predictions characterized by relative maximum errors that decrease as $M$ increases. For example, Eq. [11] predicts a maximum departure of the prediction from the measured value that decreases from 80 to $27 \%$ as $M$ increases from the minimum $\left(0.00012 \mathrm{~kg} \mathrm{~m}^{-2}\right)$ to the maximum $\left(21.7 \mathrm{~kg} \mathrm{~m}^{-2}\right)$ measured value. For this reason, despite that soil erosion models are usually able to better predict high soil losses than low ones, for the USLE-MM and CSI model the effectiveness coefficient $e$ decreased as $M$ increased. Table 3 lists $e$ values for soil loss measurements arranged by using three ranges with boundaries at 0.01 and $1 \mathrm{~kg} \mathrm{~m}^{-2}$. For both USLE versions (calibrated and uncalibrated), instead, according to the original criterion, $e$ increases as $M$ increases while, using the new criterion, none of the predictions for $M \leq 0.01 \mathrm{~kg} \mathrm{~m}^{-2}$ was acceptable and only for the uncalibrated USLE similar $e$ values were calculated for the two higher ranges. For $M>1 \mathrm{~kg} \mathrm{~m}^{-2}$, Table 3 also highlights that, for both criteria, the USLE-MM is characterized by the highest $e$ values, and the calibrated USLE has effectiveness coefficients that are practically equal to those of the USLE-MM. Therefore, the $e$ values listed in Table 3 demonstrate that for estimating the highest soil loss values $\left(M>1 \mathrm{~kg} \mathrm{~m}^{-2}\right)$, a runoff-driven model could be less effective (CSI model) or with a similar effectiveness (USLE-MM) than an at-site calibrated USLE.

For testing the dynamic behavior of the criteria's response and the representativeness of the checked performance of the three soil erosion models at the sampled site, the effectiveness coefficients were also calculated by using Databases 1 and 3, and the corresponding values are plotted in Fig. 4. For both criteria, the order of the models' reliability did not vary and, for a given model, differences in terms of $e$ were relatively low (the difference between the maximum and the minimum values was $0.01-0.06$ for the new criterion and $0.02-0.07$ for the original criterion). Including additional measurements moving from Database 1 to Database 3 did not appreciably modify the checked performance of the models, which, according to both applicative criteria of the physical model concept, can be considered representative of the reliability of these models at the sampled site.

Finally, these results supported the hypothesis of Nearing (2000) that, with the original applicative criterion of the physical model concept, a calibrated model (the USLE-MM or the CSI model, Fig. 4a) might perform better than $e=0.6$. For the uncalibrated USLE, the effectiveness coefficient of 0.47 to 0.48 was in line with the suggestion that $e=0.6$ is the highest effectiveness coefficient that can be expected with an uncalibrated model (Nearing,
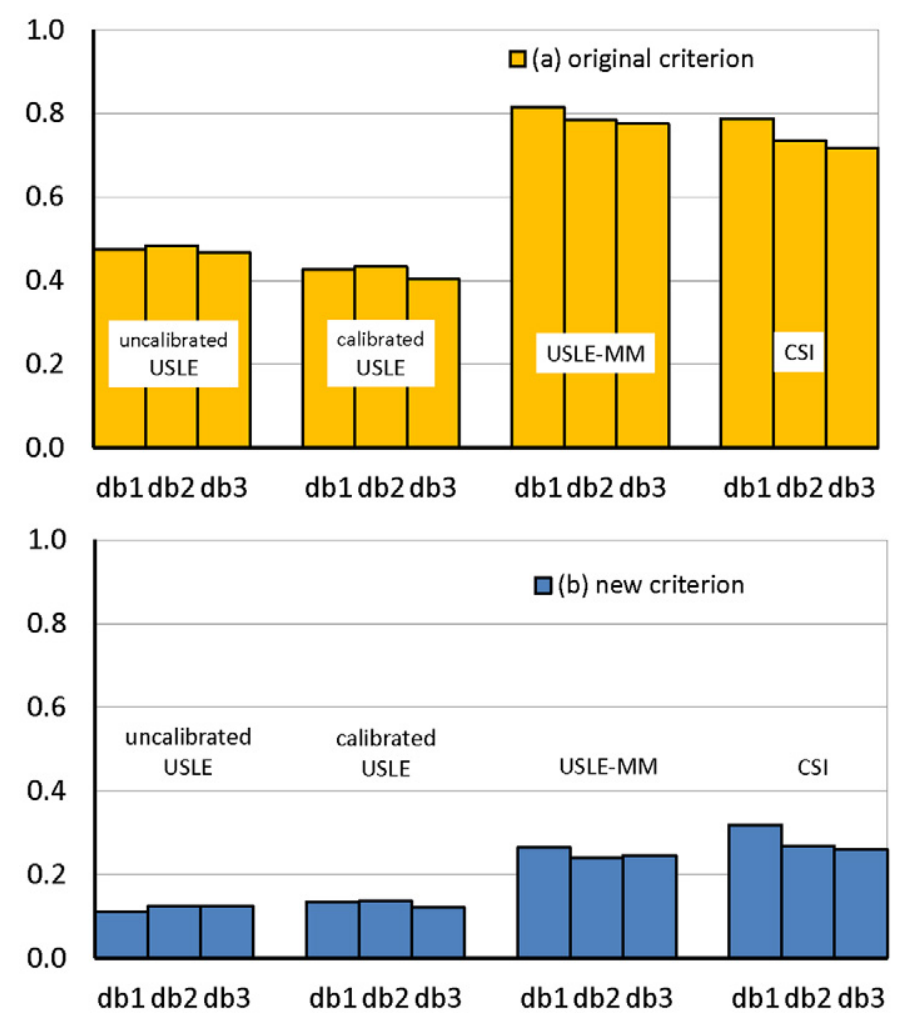

Fig. 4. Values of the effectiveness coefficient $e$ calculated by (a) the original (Nearing, 2000) and (b) the new (Bagarello et al., 2013a) criterion for event soil loss measurements included in Database 1, Database 2, and Database 3.

2000). Another point to be noted is that using the calibrated USLE $(e=0.40-0.43)$ does not imply that $e>0.6$ should be expected in any case. This result is due to a calibration procedure that does not improve the estimate of the lowest soil loss values $\left(M<1 \mathrm{~kg} \mathrm{~m}^{-2}\right)$. Applying the new criterion, $e$ values of 0.11 to 0.12 were obtained for the uncalibrated USLE and $e$ values of 0.12 to 0.32 for the calibrated models (Fig. 4b). For the new criterion, the expected $e$ value discriminating uncalibrated from calibrated models is 0.12 . Developing a larger database including other experimental areas would be necessary to establish what order of effectiveness values is expected from uncalibrated and calibrated erosion models by using the new criterion.

\section{Conclusions}

Testing the applicability of soil erosion models should take into account that, when comparing measured erosion rates to predicted values, a portion of any difference between the two is expected to be due to model error but a portion will be due to unexplained variance of the measured sample value from the representative mean value for a particular treatment. The physical model, represented by a replicated soil loss measurement, is able to quantify the natural variation of the plot soil loss. In the present investigation, two different applicative criteria of the physical model concept for evaluating predictions by soil erosion models were compared. The 
original criterion was developed in the United States and is based on the relative differences between the predicted and the measured soil loss, while the new one was recently developed by using an Italian database and is based on the absolute difference between the predicted and the measured soil loss.

Three soil erosion empirical models (the USLE, the USLE-MM, and the CSI model) were applied to estimate soil losses, which were measured, at the event temporal scale, on plots of different length and steepness at the Sparacia station.

The greater selectivity of the new criterion compared with the original one was analytically demonstrated and empirically quantified. The order of reliability of the three models depended on the evaluation criterion, but, in both cases, minor differences in the performance of the calibrated USLE-MM and CSI model were detected and the calibrated and uncalibrated versions of the USLE performed worse than the other two models. A frequency occurrence of absolute difference between measured and predicted soil loss by the replicated plot of 0.87 was determined to be the discriminating value between the relative selectivity of the two compared criteria. For decreasing values of the frequency occurrence from 0.87 to 0.5 , which practically yields Eq. [11], the selectivity of the new criterion increases, i.e., it becomes more and more restrictive than the original one, while the opposite occurs for frequency values $>0.87$.

For both criteria, the effectiveness coefficient for the USLE-MM and CSI model was found to decrease with the measured soil loss, while it tended to increase for the two versions of the USLE. Therefore, for the USLE-MM and CSI model, although the prediction relative error generally decreased as the soil loss magnitude increased, the rate of this reduction was lower than that of the maximum error allowed by the evaluation criteria. Predictions by the uncalibrated USLE were always poor, while the performance of the calibrated USLE was high for the highest measured soil losses. For these last values, a runoff-driven model could be less effective (CSI model) or similarly effective (USLE-MM) than the at-site calibrated USLE.

A time independence of the effectiveness coefficient was detected for both criteria, which implies that the checked performance of the three tested models could be considered representative of their capability in predicting soil losses at the sampled site.

The present investigation established that, when the original criterion is used, the expected effectiveness coefficient for a calibrated model can be $>0.6$, while it is surely $<0.6$ for an uncalibrated model. In other words, the general validity of the discriminating value suggested by Nearing (2000) was supported.

With reference to the new criterion, developing a larger database including other experimental areas would be necessary to establish what order of effectiveness values is expected for uncalibrated and calibrated erosion models. More generally, this is advisable to confirm the general validity of the new criterion because it was based on data collected only in two experimental stations, both located in Italy. However, the new criterion allowed to determine that an effectiveness coefficient of 0.12 discriminates between uncalibrated and calibrated models for the sampled site of Sparacia.

In principle, both the original and the new criterion, although characterized by a different selectivity level, are useful to evaluate soil loss predictions. Thus, use of the original or the new criterion should depend on the desired accuracy level of soil loss estimates for the purposes of the model's application. For example, erosion models should be able to very accurately predict the highest soil loss values, which are responsible for large fractions of the total soil loss from an area of interest over long periods of time. These predictions have practical importance because they could allow improvement of the design of soil conservation practices in that area, and thus the best soil erosion model among the available ones has to be used. In principle, because the models' accuracy ranking depends on the evaluation criterion, and the new criterion is more restrictive than the original one, the former is advisable to be used in this case. This conclusion was confirmed by the developed analysis based on all measured data, while a different result was derived from analysis of the highest soil losses. In this latter case, both criteria gave the same accuracy ranking of the applied models.

The two physical model criteria considered in this investigation were deduced by two different databases. To increase the strength of this comparison, it is advisable to calibrate the two criteria using a single database including all available measured soil loss data.

\section{Acknowledgments}

All authors set up the research and contributed to analyzing the data and writing the manuscript.

\section{References}

Bagarello, V., G.V. Di Piazza, and V. Ferro. 2004. Manual sampling and tank size effects on the calibration curve of plot sediment storage tanks. Trans. ASAE 47:1105-1112. doi:10.13031/2013.16583

Bagarello, V., G.V. Di Piazza, V. Ferro, and G. Giordano. 2008. Predicting unit plot soil loss in Sicily, South Italy. Hydrol. Processes 22:586-595. doi:10.1002/hyp.6621

Bagarello, V., C. Di Stefano, V. Ferro, G. Giordano, M. lovino, and V. Pampalone. 2012. Estimating the USLE soil erodibility factor in Sicily, South Italy. Appl. Eng. Agric. 28:199-206. doi:10.13031/2013.41347

Bagarello, V., C. Di Stefano, V. Ferro, P.I.A. Kinnell, V. Pampalone, P. Porto, and F. Todisco. 2011. Predicting soil loss on moderate slopes using an empirical model for sediment concentration. J. Hydrol. 400:267-273. doi:10.1016/j.jhydrol.2011.01.029

Bagarello, V., and V. Ferro. 1998. Calibrating storage tanks for soil erosion measurement from plots. Earth Surf. Processes Landforms 23:1 151-1170. doi:10.1002/(SICI) 1096-9837(199812)23:13<1151::AIDESP929>3.0.CO;2-7

Bagarello, V., and V. Ferro. 2004. Plot-scale measurement of soil erosion at the experimental area of Sparacia (southern Italy). Hydrol. Processes 18:141-157. doi:10.1002/hyp.1318

Bagarello, V., and V. Ferro. 2012. Testing the "physical model concept" by soil loss data measured in Sicily. Catena 95:1-5. doi:10.1016/j.catena.2012.02.017

Bagarello, V., and V. Ferro. 2017. Supporting USLE-MM reliability by an- 
alyzing soil loss measurement errors. Hydrol. Processes 31:847-853. doi:10.1002/hyp.11063

Bagarello, V., V. Ferro, and G. Giordano. 2010. Testing alternative erosivity indices to predict event soil loss from bare plots in southern Italy. Hydrol. Processes 24:789-797.

Bagarello, V., V. Ferro, G. Giordano, F. Mannocchi, V. Pampalone, and F. Todisco. 2013a. A modified applicative criterion of the physical model concept for evaluating plot soil erosion predictions. Catena 126:5358. doi:10.1016/j.catena.2014.10.021

Bagarello, V., V. Ferro, and V. Pampalone. 2015. A new version of the USLEMM for predicting bare plot soil loss at the Sparacia (South Italy) experimental site. Hydrol. Processes 29:4210-4219. doi:10.1002/hyp.10486

Bagarello, V., V. Ferro, and V. Pampalone. 2013b. A new expression of the slope length factor to apply USLE-MM at Sparacia experimental area (southern Italy). Catena 102:21-26. doi:10.1016/j.catena.2011.06.008

Carollo, F.G., C. Di Stefano, V. Ferro, V. Pampalone, and F. Sanzone. 2016. Testing a new sampler for measuring plot soil loss. Earth Surf. Processes Landforms 41:867-874. doi:10.1002/esp.3866

Di Stefano, C., V. Ferro, and V. Pampalone. 2017a. Applying the USLE family of models at the Sparacia (South Italy) experimental site. Land Degrad. Dev. 28:994-1004. doi:10.1002/ldr.2651

Di Stefano, C., V. Ferro, and V. Pampalone. 2017b. Testing the USLE-M family of models at the Sparacia (South Italy) experimental area. J. Hydrol. Eng. 22(8):05017012. doi:10.1061/(ASCE)HE.1943-5584.0001535

Foster, G.R., D.K. McCool, K.G. Renard, and W.C. Moldenhaver. 1981. Conversion of the Universal Soil Loss Equation to SI metric units. J. Soil Water Conserv. 36:355-359.

Gao, G.Y., B.J. Fu, Y.H. LÜ, Y. Liu, S. Wang, and J. Zhou. 2012. Coupling the modified SCS-CN and RUSLE models to simulate hydrological effects of restoring vegetation in the Loess Plateau of China. Hydrol. Earth Syst. Sci. 16:2347-2364. doi:10.5194/hess-16-2347-2012

Hann, M.J., and R.P.C. Morgan. 2006. Evaluating erosion control measures for biorestoration between the time of soil reinstatement and vegetation establishment. Earth Surf. Processes Landforms 31:589-597. doi:10.1002/esp.1353

Kinnell, P.I.A. 1997. Runoff ratio as a factor in the empirical modeling of soil erosion by individual rainstorms. Aust. J. Soil Res. 35:1-13.

Kinnell, P.I.A. 2003. Event erosivity factor and errors in erosion predictions by some empirical models. Aust. J. Soil Res. 41:991-1003. doi:10.1071/SR02123

Kinnell, P.I.A. 2007. Runoff dependent erosivity and slope length factors suitable for modeling annual erosion using the Universal Soil Loss Equation. Hydrol. Processes 21:2681-2689. doi:10.1002/hyp.6493
Kinnell, P.I.A. 2016. Comparison between the USLE, the USLE-M and replicate plots to model rainfall erosion on bare fallow areas. Catena 145:39-46. doi:10.1016/j.catena.2016.05.017

Kinnell, P.I.A., and L.M. Risse. 1998. USLE-M: Empirical modeling rainfall erosion through runoff and sediment concentration. Soil Sci. Soc. Am. J. 62:1667-1672. doi:10.2136/sssaj1998.03615995006200060026x

Meyer, L.D., and W.C. Harmon. 1992. Soil erosion varies during the crop year. Trans. ASAE 35:459-464. doi:10.13031/2013.28621

Nearing, M.A. 1997. A single continuous function for slope steepness influence on soil loss. Soil Sci. Soc. Am. J. 61:917-919. doi:10.2136/sssaj1997.03615995006100030029x

Nearing, M.A. 1998. Why soil erosion models over-predict small soil losses and under-predict large soil losses. Catena 32:15-22. doi:10.1016/S0341-8162(97)00052-0

Nearing, M.A. 2000. Evaluating soil erosion models using measured plot data: Accounting for variability in the data. Earth Surf. Processes Landforms 25:1035-1043. doi:10.1002/1096-9837(200008)25:9<1035::AIDESP121>3.0.CO;2-B

Nearing, M.A., G. Govers, and L.D. Norton. 1999. Variability in soil erosion data from replicated plots. Soil Sci. Soc. Am. J. 63:1829-1835. doi:10.2136/sssaj1999.6361829x

Renard, K.G., G.R. Foster, G.A. Weesies, D.K. McCool, and D.C. Yoder. 1997. Predicting soil erosion by water: A guide to conservation planning with the Revised Universal Soil Loss Equation (RUSLE). Agric. Handb. 703. US Gov. Print. Office, Washington, DC.

Risse, L.M., M.A. Nearing, A.D. Nicks, and J.M. Laflen. 1993. Error assessment in the Universal Soil Loss Equation. Soil Sci. Soc. Am. J. 57:825-833. doi:10.2136/sssaj1993.03615995005700030032x

Sanchis, M.P.S., D. Torri, L. Borselli, and J. Poesen. 2007. Climate effects on soil erodibility. Earth Surf. Processes Landforms 33:1082-1097. doi:10.1002/esp.1604

Soil Survey Staff. 2006. Keys to Soil Taxonomy. 10th ed, NRCS, Washington, DC.

Tiwari, A.K., L.M. Risse, and M.A. Nearing. 2000. Evaluation of WEPP and its comparison with USLE and RUSLE. Trans. ASAE 43:1129-1135. doi:10.13031/2013.3005

Wischmeier, W.H., C.B. Johnson, and B.V. Cross. 1971. A soil erodibility nomograph for farmland and construction sites. J. Soil Water Conserv. 26:189-193.

Wischmeier, W.H., and D.D. Smith. 1978. Predicting rainfall erosion losses: A guide to conservation planning. Agric. Handb. 537. US Gov. Print Office, Washington, DC. 